\title{
A Simple and Effective Method of the Synthesis of Nanosized $\mathrm{Fe}_{2} \mathrm{O}_{3}$ particles
}

\author{
Miss Ritu \\ Department of Chemistry, Maharishi Markendeshwer University, Mullana -133203, (Haryana),India.
}

\begin{abstract}
Nanosized Iron oxide is prepared by using precipitation method from iron nitrate and liquid ammonia. Thermal analysis shows that synthesized iron oxide shows some weight loss and oxide undergoing decomposition, dehydration or any physical change from TGA curve we observe that Iron oxide shows stable weight loss above $400^{\circ} \mathrm{C}$. In DTA curve also, there is exothermic and endothermic peak. Which shows phase transition, solid state reaction or any chemical reaction occurred during heating treatment. Morphology is observed by scanning electron microscopy (SEM) shows particles are nanosized. Further morphology observation by Transmission Electron Microscopy (TEM) revels that Iron Oxide has the corundum $\left(\mathrm{Al}_{2} \mathrm{O}_{3}\right)$ structure. Magnetic measurements shows that iron oxide has five unpaired electron and strongly paramagnetic character.
\end{abstract}

Keywords:Corundum, Haematite, Scanning Electron Microscopy (SEM), Transmission Electron Microscopy (TEM).

\section{Introduction}

The first requirement of any novel study of nanoparticulated oxides is the synthesis of the material. The development of systematic studies for the synthesis of oxide nanoparticles is a current challenge ${ }^{[1-2]}$

Iron oxide nanaoparticles are iron oxide particles with superparamagnetic properties. The two main forms are magnetite and oxidized form maghemite. Magnetite has inverse spinal structure with oxgen forming face centered cubic crystal system. Maghemite has cubic unit cell.A number of specific methods have been developed among which those broadly in use are: Co-precipitation methods ${ }^{[3-9]}$ Sol-gel processing ${ }^{[10-16]}$ Microemulsion technique ${ }^{[17-23]}$ photo CVD methodologies ${ }^{[24]}$ and crystalline growth ${ }^{[25]}$. In Solvothermal methods metal complexes are decomposed thermically either by boiling in an inert atmosphere or using an autoclave with the help of pressure. Gas-solid transformation methods with broad use in the context of ultrafine oxide powder synthesis are restricted to chemical vapor deposition (CVD) and pulsed laser deposition (PLD).

$\mathrm{Fe}$ and $\mathrm{O}$ form a number of phases, e.g., $\mathrm{FeO}$ (wustite); $\mathrm{Fe}_{3} \mathrm{O}_{4}$ (magnetite), $\mathrm{Fe}_{2} \mathrm{O}_{3}$ (hematite), $\mathrm{Fe}_{2} \mathrm{O}_{3}$ (maghemite). The latter phase is synthetic while remaining oxides occur in nature. The $\mathrm{Fe}-\mathrm{O}$ phase diagram shows the predominance of the $\mathrm{Fe}_{2} \mathrm{O}_{3}$ stiochiometry for most temperature and pressure preparation conditions [26]. Most physico-chemical studies are centered in the alpha (corundum structure with a distorted hexagonal anion closed - packed) and gamma (cubic inverse spinel) phases. Size stability of the polymorphs has been studied but there is still a lack of consensus in a significant number of issues; particularly related to the existence of nano-particles with alpha structure.

Magnetic nanoparticles are of great interest for researchers form a broad range of disciplines including data storage, catalysis and magnetic fluids. Currently magnetic nanoparticles are also used in important bioapplications like clinic diagnosis and MRI therapy. However, it is technological challenge to control size, dispersibility, stability and shape.

Iron oxide has applications in paints, shoe polish , Rubber , concrete, leather , medicines , lipstic , nutrients and feeds, body and face cream, Talcam powder, ATM cards, magnet, electronic parts, audio and video cassette tape.

\section{Experimental Detail}

$500 \mathrm{ml}$ of $0.5 \mathrm{M}$ solution of $\mathrm{Fe}\left(\mathrm{NO}_{3}\right)_{3}$ was taken and aquous ammonia was added drop wise with constant stirring until the $\mathrm{pH}$ of the solution reached to 10 . The precipitate thus obtained were filtered on buckner funnel and washed several times with distilled water. The precipitates were dried in oven at $70^{\circ} \mathrm{C}$ for 24 hrs and were calcined at $500^{\circ} \mathrm{C}$ in a muffle furnance for 5 hours. Obtained material was ground and sieved through 100 mesh size sieve.

\section{Results And Discussion}

Equipments

The power X-ray diffraction patterns were recorded using Rigaku rotating anode Ru-H3R X-ray diffractometer as well as Brucker D8 high resolution diffractionate and PAN analytical X'perts Pro 
diffractometer employing $\mathrm{CuK \alpha}\left(\lambda=1.5404 \mathrm{~A}^{0}\right)$ radiation. In the present work, TEM has been used for nanostructural investigation of the synthesized oxides at high magnifications. The instrument used for analysis was Hitachi H7500. The surface morphology of Iron oxide prepared by precipitation method was investigated by using scanning Electron Microscope Quanta 200 FEG (FEI Netherlands).

\section{X-Ray Studies}

$\mathrm{X}$-Ray diffraction of synthesized oxide is shown in figure (1) X-ray pattern of pure iron oxide indicates that iron oxide is in the forms of $\mathrm{Fe}_{2} \mathrm{O}_{3}$ (Fig. 1). In X-ray diffraction, some prominent peaks were considered and corresponding d value $(3.670460,2.69530,2.51100 \ldots \ldots \ldots$. were compared (Table-1). The Fe2O3 formed was found to be $\alpha-\mathrm{Fe}_{2} \mathrm{O}_{3}$ (Haematite) $\alpha-\mathrm{Fe}_{2} \mathrm{O}_{3}$ has the corundum $\left(\mathrm{Al}_{2} \mathrm{O}_{3}\right)$ structure in which each iron atom is surrounded octahedral by six oxygen atoms, the latter being in hexagonal close packed array.

\section{Magnetic Measurement}

The magnetic measurements are used to decide the exact electronic configuration. The values of magnetic moment observed for metal oxide are listed in Table (2). The magnetic moment for iron oxide was found to be 5.82 B.M. this value of magnetic moment supports the fact that our oxide formed is $\mathrm{Fe}_{2} \mathrm{O}_{3}$ with actual magnetic moment 4.92 B.M. This indicates presence of five unpaired electrons and strongly paramagnetic character.

\section{Thermal Analysis}

Thermal analysis includes a group of techniques in which a physical property of a substance is measured as a function of temperature or time while the substance is subjected to a controlled temperature programme. The analysis involves thermogravity (TG), differential thermal analysis (DTA) and derivative Thermogravimetry (DTG). Thermal Gravimetric studies of the calcined oxides prepared were done between a temperature range of $10-1000^{\circ} \mathrm{C}$ under $\mathrm{N}_{2}$ atmosphere. The TGA/DTA curves of the oxides are shown in Fig. (2). The maximum total weight loss observed for Iron oxide and their corresponding temperature is summarized in Table 3. Results showed that in the synthesized oxides shows some weight loss and oxide undergoing decomposition, dehydration or any physical change. From TGA curve we observed that Iron oxides shows stable weight loss above $500^{\circ} \mathrm{C}$. It is concluded form TGA curve that there is a loss of three water molecule during the process.

In DTA curve also, there is exothermic and endothermic peak which shows phase transition, solid state reach on any chemical reaction occurred during heating treatment and it is concluded from TGA curve that there is loss of two water molecules during process.

Scanning electron microscopy shows the surface morphology of Iron Oxide Fig. (3)

\section{TEM Studies}

It shows that the $\mathrm{Fe}_{2} \mathrm{O}_{3}$ formed was found to be $\alpha-\mathrm{Fe}_{2} \mathrm{O}_{3}$ (Heamatite) Fig. (4). $\alpha-\mathrm{Fe}_{2} \mathrm{O}_{3}$ has the corundum $\left(\mathrm{Al}_{2} \mathrm{O}_{3}\right)$ structure in which each iron atom is surrounded octahedrally by six oxygen atoms, the latter being in hexagonal close packed array and size of the obtained nanoparticles is in the range 87.5 to $154.1666 \mathrm{~nm}$ (Table 4).

\section{Conclusion}

Based on the obtained results formation of nanosized iron oxide by using precipitation method is having particle size 87.5 to $154.1666 \mathrm{~nm}$ It has been concluded that $\alpha-\mathrm{Fe}_{2} \mathrm{O}_{3}$ has the corundum $\left(\mathrm{Al}_{2} \mathrm{O}_{3}\right)$ structure in which each iron atom is surrounded octahedral by six oxygen atoms, the latter being in hexagonal close packed array. It has five unpaired electron and strongly paramagnetic in nature.

$\alpha-\mathrm{Fe}_{2} \mathrm{O}_{3}$ Shows some weight loss and oxide undergoing decomposition, dehydration or any physical change. From TGA curve we observe that Iron oxide shows table weight loss above $400^{\circ} \mathrm{C}$.

\section{TABLE-1 X-RAY DIFFRACTION DATA OF IRON OXIDE}

\begin{tabular}{|l|l|l|l|l|}
\hline $\mathrm{S} . \mathrm{N}$ & $\begin{array}{l}\mathrm{d}=\lambda / 2 \operatorname{Sin} \theta \\
(\text { Observed })\end{array}$ & $\begin{array}{l}\mathrm{d}=\lambda / 2 \operatorname{Sin} \theta \\
\text { (Reported) }\end{array}$ & $\begin{array}{l}\mathrm{I} / \mathrm{I}_{\mathrm{O}} \mathrm{x} 100 \% \\
\text { Observed }\end{array}$ & $\begin{array}{l}\mathrm{I} / \mathrm{I}_{\mathrm{O}} \times 100 \% \\
\text { Reported }\end{array}$ \\
\hline 1 & 3.670460 & 3.67462 & 58.75874 & 58.75875 \\
\hline 2 & 2.69530 & 2.69534 & 99.99997 & 99.99999 \\
\hline 3 & 2.51100 & 2.51102 & 63.16315 & 63.16316 \\
\hline 4 & 2.28950 & 2.28957 & 33.43342 & 33.43343 \\
\hline 5 & 2.20170 & 2.20176 & 3.40339 & 3.40340 \\
\hline 6 & 2.07320 & 2.0732 & 0.30029 & 0.30030 \\
\hline
\end{tabular}


A simple and effective method of the synthesis of nanosized $\mathrm{Fe}_{2} \mathrm{O}_{3}$ particles

\begin{tabular}{|l|l|l|l|l|}
\hline 7 & 1.8370 & 1.83731 & 6.10608 & 6.10610 \\
\hline 8 & 1.69180 & 1.69186 & 18.01800 & 18.01801 \\
\hline 9 & 1.63220 & 1.63224 & 0.70068 & 0.70070 \\
\hline 10 & 1.59871 & 1.59872 & 2.70268 & 2.70270 \\
\hline 11 & 1.48275 & 1.59872 & 18.11809 & 18.11811 \\
\hline 12 & 1.44975 & 1.48275 & 9.70969 & 9.70970 \\
\hline 13 & 1.41064 & 1.44975 & 0.30028 & 0.30030 \\
\hline 14 & 1.41064 & 1.41065 & 2.70268 & 2.70270 \\
\hline 15 & 1.34767 & 1.34768 & 7.50748 & 7.50750 \\
\hline 16 & 1.34767 & 1.30996 & 0.30028 & 0.30030 \\
\hline 17 & 1.30995 & 1.26018 & 7.60758 & 7.60760 \\
\hline 18 & 1.26017 & 1.2552 & 7.50748 & 7.50750 \\
\hline 19 & 1.2551 & 1.22486 & 0.30028 & 0.30030 \\
\hline 20 & 1.22484 & 1.22485 & 7.60758 & 7.60760 \\
\hline
\end{tabular}

TABLE 2: OBSERVATIONS ON MAGNETIC SUSCEPTIBILITIES OF SYNTHESIZED NICKEL

Experimental Conditions:

OXIDE

Applied Magnetic field= 5.0 Kilo gauss

Temperature $=296 \mathrm{~K}$

\begin{tabular}{|l|l|l|l|l|l|}
\hline $\begin{array}{c}\text { Sr.N } \\
\mathrm{o}\end{array}$ & $\begin{array}{l}\text { Name of } \\
\text { Oxide }\end{array}$ & $\begin{array}{l}\mathrm{R}=\mu_{1}-\mu_{2} \\
(\mathrm{e} . \mathrm{m} . \mathrm{u})\end{array}$ & $\begin{array}{l}\mathrm{W}=\mathrm{w}_{1}-\mathrm{W}_{2} \\
(\mathrm{gm})\end{array}$ & $\begin{array}{l}\mu_{\text {calculated }} \\
=\mu_{1}-\mu\end{array}$ & $\begin{array}{l}\mu_{\text {observed }} \\
\text { (B.M. })\end{array}$ \\
\hline 1 & $\begin{array}{l}\text { Iron } \\
\text { Oxide }\end{array}$ & $\begin{array}{l}0.741 \mathrm{x} 10 \\
-2\end{array}$ & 0.01654 & 5.82 & 5.92 \\
\hline
\end{tabular}

$\mu_{\text {calculated }}=\sqrt{ } \mathrm{n}(\mathrm{n}+2)$ and $\mu_{\text {observed }}={ }^{2.84} \sqrt{\mathrm{RTM}} / \mathrm{HW}$

Where

$\mathrm{n}=\quad$ no. of unpaired electron.

$\mathrm{R}=\quad$ Magnetic Moment in B.M.

$\mathrm{T}=$ absolute Temperature.

$\mathrm{M}=\quad$ Molecular weight

$\mathrm{H}=\quad$ Applied Magnetic Field

$\mathrm{W}=$ Weight of Sample.

TABLE: 3: OBSERVATIONS OF WEIGHT LOSS FOR IRON OXIDE AT CORRESPONDING TEMPERATURE RANGE

\begin{tabular}{|l|l|l|}
\hline Sr.No. & $\begin{array}{l}\text { Maximum \% loss in } \\
\text { weight }\end{array}$ & $\begin{array}{l}\text { Temperature } \\
\text { range }\end{array}$ \\
\hline 1 & $27.3 \%$ & $23-500$ \\
\hline 2 & $0.9 \%$ & $500-994$ \\
\hline
\end{tabular}

TABLE -4: PRACTICAL SIZE OF SYNTHESIZED IRON OXIDE AT DIFFERENT SCALES

\begin{tabular}{|l|l|l|}
\hline S.No. & Scale $50 \mathrm{~nm}$ & Scale $100 \mathrm{~nm}$ \\
\hline 1 & 87.5 & 87.8 \\
\hline 2 & 97.9166 & 95.8333 \\
\hline 3 & 112.5 & 154.16666 \\
\hline 4 & 87.5 & 87.8 \\
\hline 5 & 87.5 & 87.8 \\
\hline 6 & 97.916 & 8.78 \\
\hline 7 & 87.5 & 87.8 \\
\hline 8 & 97.916 & 95.8333 \\
\hline 9 & 87.5 & 87.8 \\
\hline 10 & 97.916 & 95.8333 \\
\hline Range & $\begin{array}{l}87.5 \mathrm{~nm} \\
112.5 \mathrm{~nm}\end{array}$ & $87.8 \mathrm{~nm}$ to $154.1666 \mathrm{~nm}$ \\
\hline
\end{tabular}




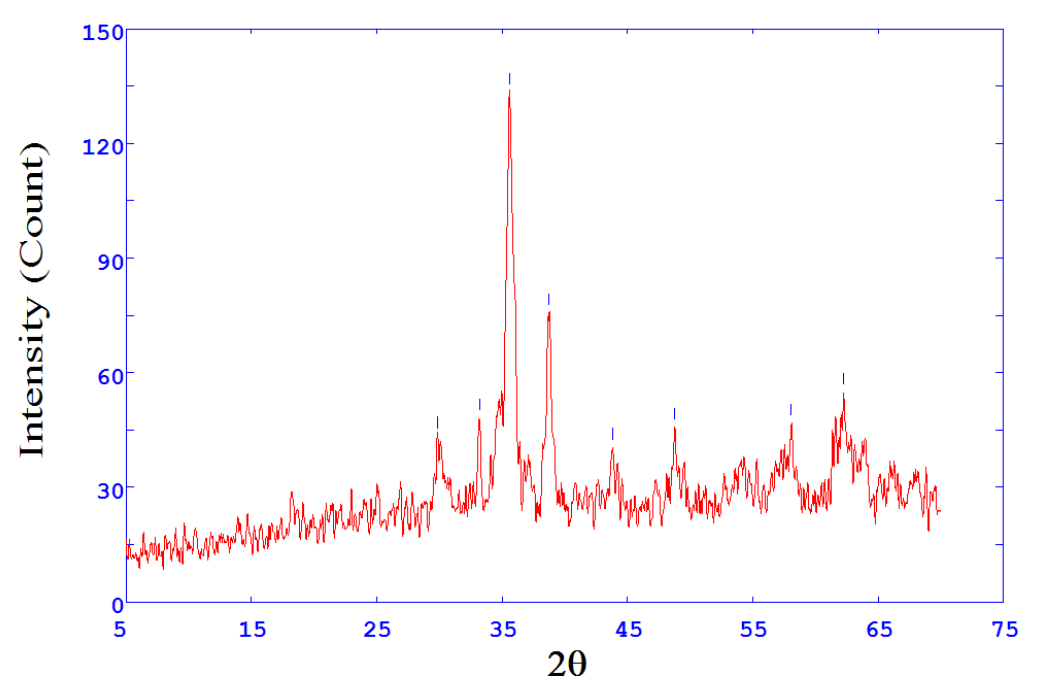

Figure 1: X-ray diffraction patterns of calcined sample after calcinations

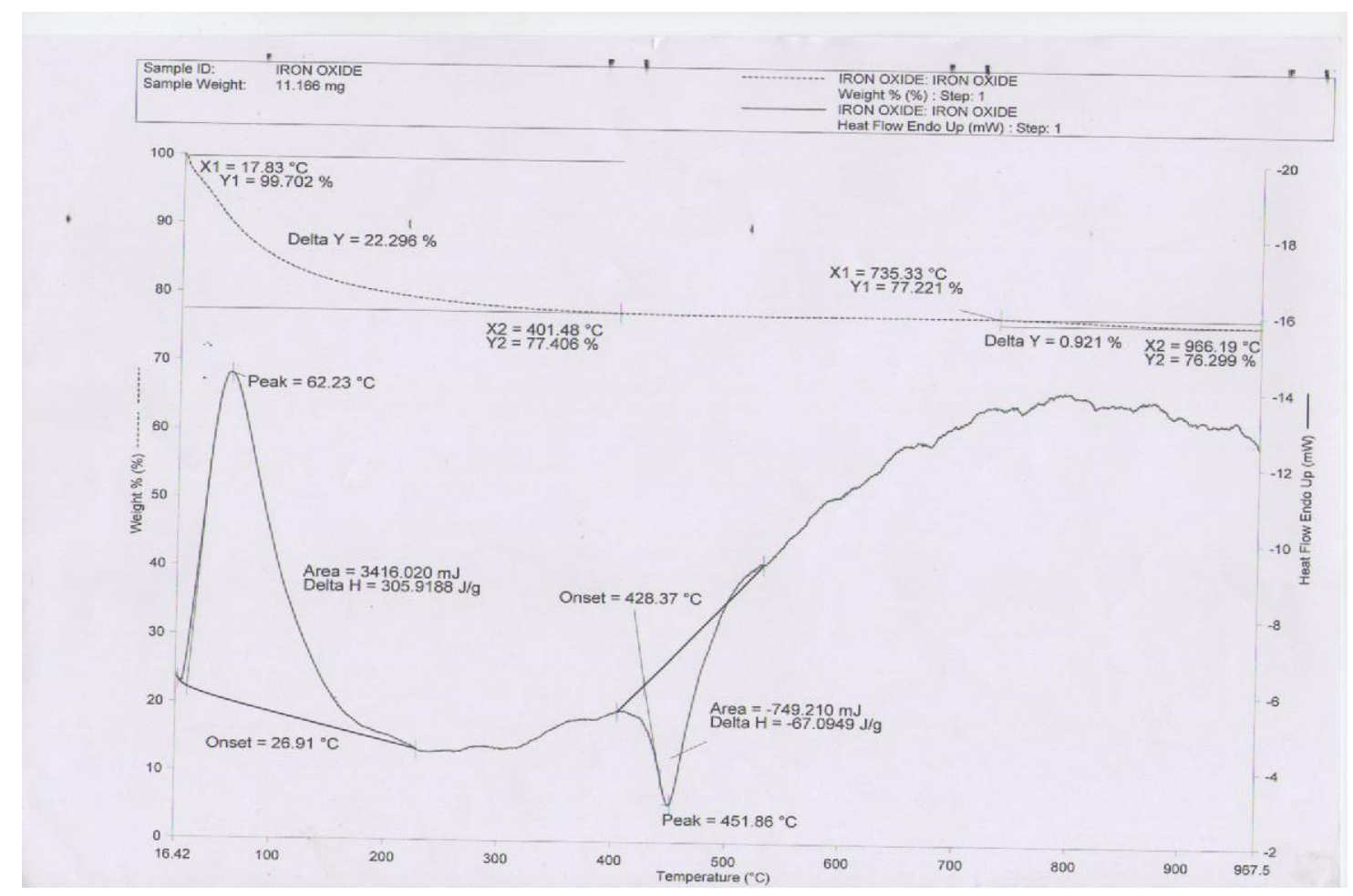

SEM Studies

Figure 2: TGA-DTA Graph of Iron Oxide 


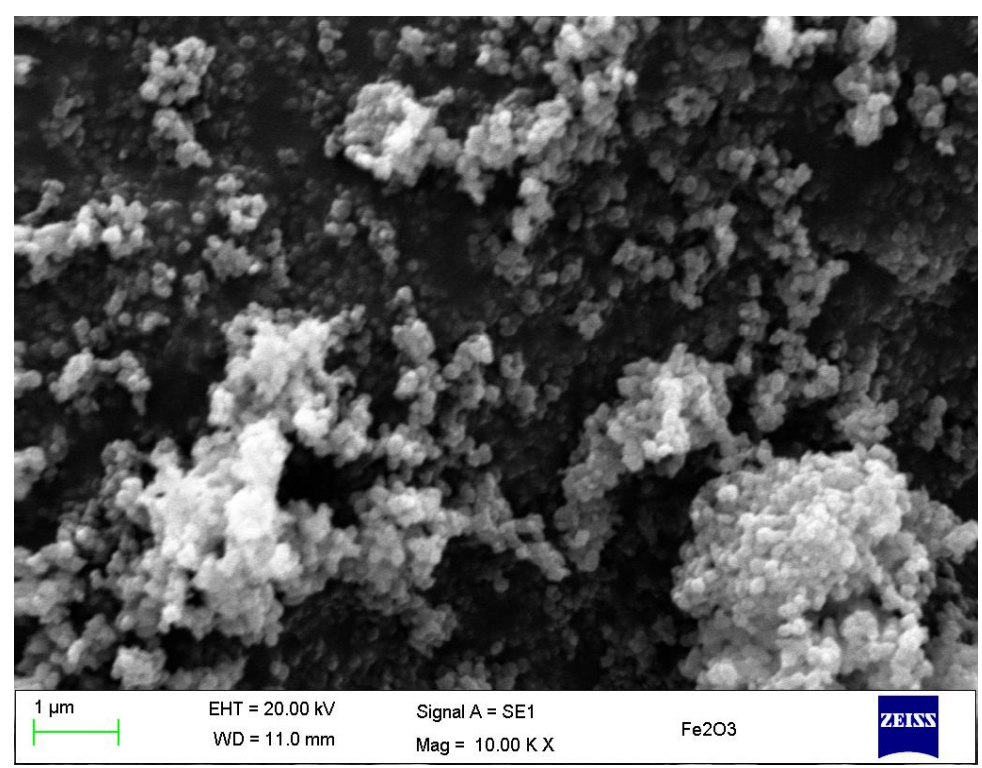

Figure 3: SEM micrographs of Iron Oxide

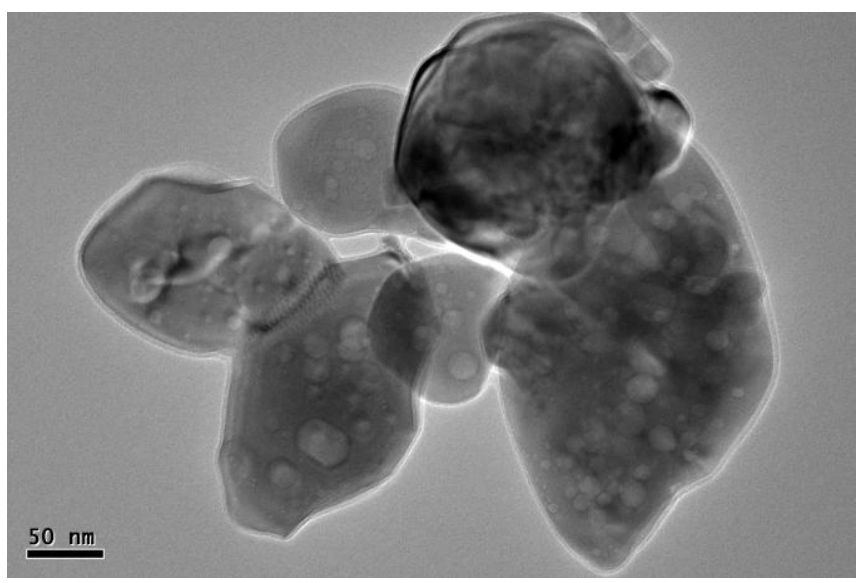

Fig. 4(a) TEM micrographs of Iron Oxide (Scale bar is $50 \mathrm{~nm}$ )

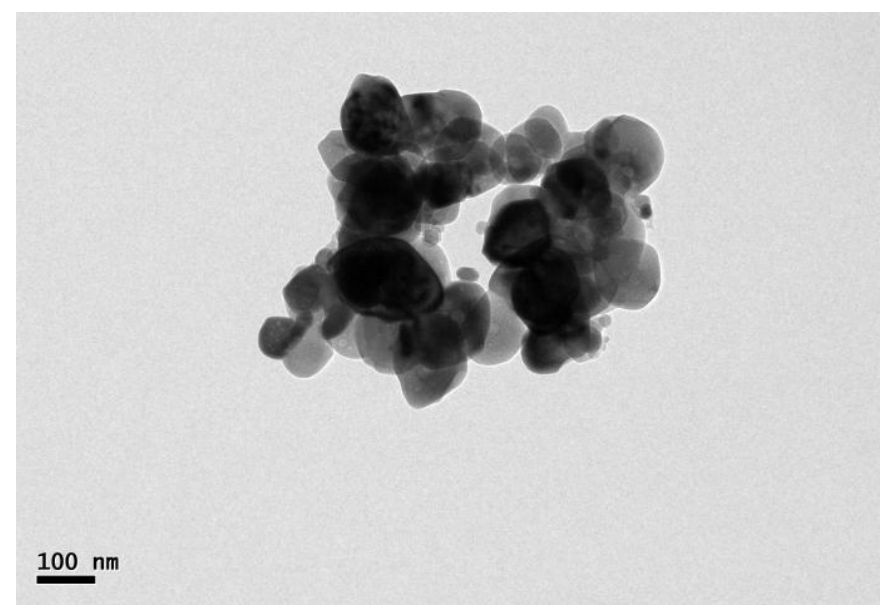

Fig: 4(b) TEM micrographs of Iron Oxide (Scale bar is 100nm) 


\section{References}

[1]. L.D. Souza, R. Richard, Synthesis of Metal - Oxide Nanoparticles Liquid-Solid Transformations in "Synthesis, Properties and Applications of Oxide Nanoparticles", Whiley, N.J. 2007 Chap. 3

[2]. S. Buzby, R.S. Franklin, S.I. Shah, Synthesis of Metal Oxide Nanoparticles, Liquid-Solid transformations in "Synthesis, Properties and Applications of Oxide Nanoparticles, Whiley, N.J. 2007, Chap. 4

[3]. K.S. Suslick, S.B. Choe, A.A. Cichowlas, M.W. Green Staff, Nature, 353 (1991) 414

[4]. J.F. Chen, Y.H. Wang, F. Gou, X.M. Wang, C. Zheng, Ind. Eng. Chem. Res. 39 (2002) 948

[5]. L.V. Integrate, M.J. Hampen-Smith, Chemistry of Advanced Materials: An overview, Whiley VCH: New York, 1998.

[6]. V. Uskokvick, M. Drofenik, Surf-Rev. Letter, 12 (2005) 239.

[7]. J. Ohring, The Material Science of Thin Films, Academic - Press, San Diego, 1992

[8]. G.K. Hubler, Mater Res Bull, 17 (1992) 25

[9]. M.G. Fernandez, X. Wang, C. Belver, J.C. Hanson, J.A.Rodriguez, J. Phys. Chem. C,111, (2007) 674

[10]. H. Zhang, J.F. Bandfield, J. Phys. Chem. C, 111 (2007) 6621

[11]. M.G. Fernandez, C. Belver, X.Wang, J.C. Hanson, J.A. Rodrighez, J. Am Chem. Soc. (2007) in Press.

[12]. B.J. Scott, G. Wirnsberger, G.D. Stocky, Chem. Matter ,13 (2001) 3140

[13]. G.C. Mather, A.A. Martinez, Transport Properties and Oxygen Handling in "Synthesis, Properties and Applications of Oxide Nanoparticles" Whiley: N.J. 2007 Chapt. 13

[14]. J.R. Weertman, R.S. Averbac, Mechanical Properties in 'Nanomaterials Synthesis, Properties and Applications, Inst. Physics Publishing; London 1996

[15]. B.M. Reddy, Redox Properties of Oxides in "Metal Oxides" CRC, Boca Raton 2006

[16]. G. Busca; The Surface Acidity and Basicity of Solid Oxides and Zeolites "Metal Oxides” CRC, Boca Raton, 2006

[17]. C. Klingshrin, Phys. Stat Sol. 244 (2007) 3027

[18]. G.P. Dransfield, Rad. Protection Dosimetry, 91 (2000) 271

[19]. J. Fan, R. Freer, J. Appl. Phys., 77 (1995) 4795

[20]. G.C. Ibanez, C. Belver, M.G. Fernandez, Nanostructural Oxides in Photo-Catalysis in "Synthesis, Properties and Applications of Oxide Nanoparticles" Whiley; N.J.; 2007 Chapt. 14

[21]. Z.L. Wang, J. Phys. Condens, Matter, 16 (2004) R. 829

[22]. X. Wu, P. Jiang, Y. Ding, W. Cai, S.S. Xie, Z.L. Wang, Adv. Mater, 19 (2007) 2319

[23]. H.K. Yadar, V. Gupta, S.P. Singh. B. Sundarakannan, R.S. Katiyar, Phys. Rev. Lett., 97 (2006) 085502

[24]. L. Jin, Z. Xu, J. Shang, X. Sun, H. Guo, Mater Sci. Eng. A. 332 (2002) 356

[25]. Y.S. Wang, P.J. Thomas P. Brien, J. Phys. Chem. B,110 (2006) 21412

[26]. W. Weiss, W. Ranke; Prog. Surf. Sci,. 70 (2002) 151 